\title{
Benefits of Pulmonary Rehabilitation in Idiopathic Pulmonary Fibrosis
}

\author{
Jeffrey J Swigris DO MSc, Diane L Fairclough DrPH, Marianne Morrison RRT CCRC, \\ Barry Make MD, Elizabeth Kozora PhD, Kevin K Brown MD, and Frederick S Wamboldt MD
}

\begin{abstract}
BACKGROUND: Information on the benefits of pulmonary rehabilitation (PR) in patients with idiopathic pulmonary fibrosis (IPF) is growing, but PR's effects on certain important outcomes is lacking. METHODS: We conducted a pilot study of PR in IPF and analyzed changes in functional capacity, fatigue, anxiety, depression, sleep, and health status from baseline to after completion of a standard, 6-week PR program. RESULTS: Six-min walk distance improved a mean \pm standard error $202 \pm 135$ feet $(P=.01)$ from baseline. Fatigue Severity Scale score also improved significantly, declining an average $1.5 \pm 0.5$ points from baseline. There were trends toward improvement in anxiety, depression, and health status. CONCLUSIONS: PR improves functional capacity and fatigue in patients with IPF. (ClinicalTrials.gov registration NCT00692796.) Key words: pulmonary rehabilitation; idiopathic pulmonary fibrosis; IPF; outcomes; functional capacity; fatigue. [Respir Care 2011;56(6):783-789. ( 2011 Daedalus Enterprises]
\end{abstract}

\section{Introduction}

Idiopathic pulmonary fibrosis (IPF) is a progressive fibrosing parenchymal lung disease that has no effective drug therapy, and the survival rate is worse than many cancers. ${ }^{1,2}$ In patients with IPF, dyspnea impairs functional capacity and profoundly decreases quality of life. . $^{3-5}$ Another bothersome, yet often overlooked, symptom in IPF patients is fatigue or low energy-or, more precisely,

\footnotetext{
Dr Swigris, Ms Morrison, and Dr Brown are affiliated with the Autoimmune Lung Center and Interstitial Lung Disease Program, National Jewish Health, Denver, Colorado. Dr Fairclough is affiliated with the Colorado Health Outcomes Program; Dr Make is affiliated with the COPD Program; and Drs Kozora and Wamboldt are affiliated with the Division of Psychosocial Medicine, University of Colorado Denver, Denver, Colorado.
}

Dr Swigris was partly supported by National Institutes of Health Career Development Award K23 HL092227. This study was partly supported by an award from the Mordecai Palliative Care Research Fund and partly by Colorado Clinical and Translational Science Award 1U11 RR05780.

The authors have disclosed no conflicts of interest.

Correspondence: Jeffrey J Swigris DO MSc, Autoimmune Lung Center and Interstitial Lung Disease Program, National Jewish Health, 1400 Jackson Street, Denver CO 80206. E-mail: swigrisj@njc.org.

DOI: $10.4187 /$ respcare.00939 "exhaustion."6 As fibrosis advances, dyspnea and fatigue worsen, patients become less and less physically active and are unable to perform physical activities (eg, dressing and bathing) without becoming severely breathless, which can lead to aerobic and skeletal muscle deconditioning, social isolation, and impaired emotional well-being. ${ }^{7}$

Pulmonary rehabilitation (PR) is a comprehensive, multidisciplinary program that uses a combination of teaching, counseling, and behavior modification techniques to improve self-management, reduce symptoms, optimize functional capacity, and increase participation in social and physical activities in patients with chronic lung disease. ${ }^{8}$ $\mathrm{PR}$ is a cornerstone of management for patients with COPD, in whom it decreases respiratory rate (by prolonging expiration). PR increases tidal volume and oxygen saturation, ${ }^{9}$ improves cardiac conditioning, increases fat-free body mass, ${ }^{10}$ makes the quadriceps more fatigue resistant, ${ }^{11}$ and enhances the efficiency of skeletal muscle function at the cellular and molecular levels. ${ }^{8}$ These effects translate to statistically significant and clinically meaningful improvements in exercise capacity, quality of life, and dyspnea. $^{8}$

Because of the lack of effective drug therapy for IPF, and building on the vast data supporting PR in COPD, there is growing enthusiasm for PR for IPF patients. In early studies of IPF patients, PR (or an exercise program similar to that commonly implemented in PR) improved 
dyspnea, functional capacity, and quality of life. ${ }^{12-14} \mathrm{We}$ conducted a pilot study to test the hypothesis that a standard 6-week PR program would improve functional capacity, fatigue, anxiety, depression, sleep, and quality of life in IPF patients.

\section{Methods}

This study was approved by the institutional review board of National Jewish Health, and each subject provided written informed consent.

\section{Subjects}

In 2008 and 2009 we recruited from the Denver metropolitan area a convenience cohort of 21 patients with IPF. Our recruitment goal was 20 subjects. Subjects who were not patients in the Interstitial Lung Disease Program at National Jewish Health learned about the study at http:// ClinicalTrials.gov. The diagnosis of IPF was made in accordance with accepted criteria ${ }^{1}$ and confirmed by us via review of primary data. The inclusion criteria were:

- Diagnosis of IPF: no identifiable cause for lung fibrosis, and usual interstitial pneumonia lung injury confirmed by the characteristic pattern on high-resolution computed tomogram or via surgical lung biopsy

- PR not completed within the last 2 years

- Ability to walk

We excluded patients with conditions that precluded the safe completion of PR (eg, unstable coronary artery disease).

\section{Comparison Group}

We compared the change in 6-min walk distance (6MWD) in our cohort to that of patients in a previous study. ${ }^{15}$ The comparison group comprised 56 subjects with COPD who participated in a substudy of the National Emphysema Treatment Trial (NETT). Their mean age was $64.8 \pm 5.9$ years, and their mean percent of predicted $\mathrm{FEV}_{1}$ was $24 \pm 8 \%$, which is "very severe" (stage IV) disease in the Global Initiative for Chronic Obstructive Lung Disease staging system. The NETT substudy examined the effects of PR on cognitive function, and the subjects in the substudy underwent neurocognitive testing and performed 6-min walk tests before and after completing the NETT PR protocol.

\section{Pulmonary Rehabilitation Program}

Similar PR programs were run at each of the 6 centers at which subjects completed PR, and we verified the spe- cific content of each program. Each PR center was certified by the American Association of Cardiovascular and Pulmonary Rehabilitation, and each program consisted of an exercise component and an education component. The PR program consisted of 18 sessions over 6-8 weeks. In accordance with American Thoracic Society standards, ${ }^{8}$ and based on the NETT PR program, ${ }^{16}$ the exercise component at each center included aerobic (treadmill, stationary bike, or similar apparatus) and resistance (light weights, resistance bands, or machines) training; and instruction on breathing techniques (pursed-lipped, controlled, and diaphragmatic breathing), pacing, and energy conservation. The exercise regimens were individualized based on patient status and estimated ability. The aerobic component was begun at a level to achieve a heart rate $60 \%$ of predicted maximum for age; intensity and duration were gradually increased to build tolerance and confidence, with the goal of reaching maximum tolerated work load during each exercise period (goal at least $30 \mathrm{~min}$ of continuous exercise). Prior to PR, as part of routine care, each subject performed walk oximetry with oxygen titration to maintain $\mathrm{S}_{\mathrm{pO}_{2}}$ of $\geq 90 \%$. During $\mathrm{PR}$ we monitored $\mathrm{S}_{\mathrm{pO}_{2}}$ and titrated oxygen flow to ensure that saturation was $>89 \%$. The education component included sessions on oxygen use, medications, relaxation, psychosocial support, energy, nutrition, and end-of-life issues. The cost of the PR program was covered by the subjects' insurance plans.

\section{Data Collection}

Data were collected at baseline, prior to enrollment in the PR program, and after completion of the PR program. The 6-min walk test and pulmonary physiology testing were ordered by the treating physicians; some data were not collected because the tests were inadvertently not ordered. The 6-min walk test was performed according to modified American Thoracic Society guidelines. ${ }^{17}$ Forced vital capacity (FVC) and diffusing capacity of the lung for carbon monoxide unadjusted for hemoglobin $\left(\mathrm{D}_{\mathrm{LCO}}\right)$ were measured according to American Thoracic Society standards, and we report the percent-of-predicted values. ${ }^{18,19}$ In choosing health-assessment questionnaires we attempted to balance patient burden and our desire to collect data on several meaningful domains. The Fatigue Severity Scale is a 9-item questionnaire, scored from 1-7, and a higher score indicates more fatigue. ${ }^{20}$ In its initial development study, normal healthy adults scored $2.3 \pm 0.7,{ }^{20}$ and many investigators regard a score of $>4$ as evidence of important fatigue. The General Anxiety Disorder-7 scale is a 7-item questionnaire, scored from $0-21$, and a higher score indicates more severe anxiety. ${ }^{21}$ A score of 5-9 is considered mild anxiety, 10-14 is considered moderate anxiety, and $15-21$ is considered severe anxiety. ${ }^{21}$ The Patient Health Questionnaire-8 is an 8-item questionnaire, scored 
from $0-24$, and a higher score indicates more severe depression. A score of 5-9 is considered mild depression, $10-14$ is considered moderate depression, $15-19$ is considered moderately severe depression, and 20-24 is considered severe depression..$^{22}$ The Pittsburgh Sleep Quality Index is a 19-item questionnaire, scored from 0-21, and a higher score indicates greater sleep disturbance. A score $>5$ is considered to indicate important sleep disturbance. ${ }^{23}$ The Medical Outcomes Study 36-Item Short-Form (SF36 ) is a 36 -item health status questionnaire with 8 domains and 2 component summary scores (physical and mental, each of which derives from 4 of the 8 domain scores). ${ }^{22}$ As recommended by the SF-36 developers, we used an algorithm that normalizes domain scores to the 1998 United States general adult population and implements a linear T-score transformation, with a mean of 50 and standard deviation of 10. Each of the 2 summary measures is also scored by using the T-score transformation. Questionnaires were completed in a quiet room, on a computer, in our center's clinical research unit, and a research assistant was readily available to answer questions and ensure questionnaire completion prior to the subject leaving the premises.

\section{Statistical Analysis}

All statistical analyses were with statistics software (SAS 9.3.1, SAS Institute, Cary, North Carolina). Descriptive statistics were generated for baseline data. Associations between outcome measures were assessed with Pearson product-moment correlation coefficients. For the longitudinal analyses we analyzed each outcome with a repeated-measures analysis (Proc Mixed procedure in SAS) that considered assessment number (baseline and after completion of the PR program) as a categorical factor and used an unstructured variance-covariance matrix to model the covariance structure among the repeated measures by subject. We chose this procedure over an analysis of the before-and-after differences because it utilizes all available data at baseline and first follow-up, and relaxes the assumptions about the missing data, from missing completely at random to missing at random.

\section{Results}

Figure 1 displays the subject flow through the study. Seven subjects did not return for follow-up. Four of those 7 did not begin the PR program for personal scheduling reasons. One subject withdrew from PR because of increased longstanding back pain. Two subjects died during the study, both because of IPF exacerbation: one shortly after starting the PR program (and within a week of having a transtracheal oxygen catheter placed), and one shortly after completion but prior to follow-up.

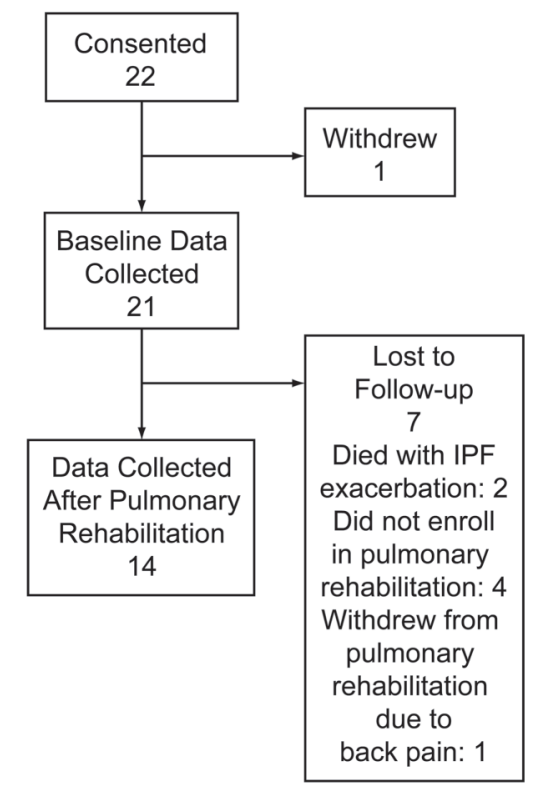

Fig. 1. Flow chart.

Table 1 shows the baseline demographics and disease characteristics. Twenty subjects were white; one was African American. Based on physiologic testing, IPF severity for the cohort was mild to moderate. 6MWD was available for 8 subjects. Among the 14 subjects from whom we obtained follow-up questionnaire data, 8 used supplemental oxygen, either 24 hours per day or only during exertion. The subjects who did not return for follow-up had a slightly greater 6MWD (782 feet vs 737 feet), lower percent-ofpredicted FVC ( $61 \%$ vs $73 \%$ ), and lower percent-of-predicted $\mathrm{D}_{\mathrm{LCO}}(27 \%$ vs $41 \%$ ) than the subjects who completed PR, but those differences were not significant $(P=.06,0.37$, and 0.10 , respectively). There was no difference in the presence and type of comorbid conditions between the subjects who did and did not return for follow-up.

Table 2 shows the correlations between various outcome variables at baseline. There were moderately strong correlations (in the expected directions) between 6MWD and $\mathrm{S}_{\mathrm{pO}_{2}}$, fatigue, and physical health status according to the physical component summary of the SF-36, and between nadir $\mathrm{S}_{\mathrm{pO}_{2}}$ during the 6-min walk test and both percent-of-predicted $\mathrm{D}_{\mathrm{LCO}}$ and the physical component summary score. Sleep quality was moderately correlated with percent-of-predicted FVC. There were several moderately strong correlations among the measures for fatigue, anxiety, depression, sleep, energy level, and physical health status.

\section{Change in 6-Minute Walk Distance}

The repeated-measures analysis-with this type of analysis, there is no case-wise deletion for missing post-PR data - showed that PR improved the mean 6MWD 202 feet 
Table 1. Baseline Characteristics of 21 Subjects With Idiopathic Pulmonary Fibrosis

\begin{tabular}{lc}
\hline \hline Age (mean \pm SD y) & $71.5 \pm 7.4$ \\
Male (no.) & 18 \\
FVC, mean \pm SD (range), \% predicted & $73 \pm 22(41-113)$ \\
$\mathrm{D}_{\text {LCO }}$, mean $\pm \mathrm{SD}$ (range), \% predicted & $38 \pm 13(12-63)$ \\
6-min walk distances, mean \pm SD & $906 \pm 488(110-1,755)$ \\
$\quad$ (range), feet & 14 \\
Surgical lung biopsy (no.) & 7 \\
Supplemental $\mathrm{O}_{2}$ 24 h/d (no.) & 7 \\
Supplemental $\mathrm{O}_{2}$ only on exertion (no.) & 13 \\
Ever smoked (no.) & 7 \\
Taking prednisone (no.) & 18 \\
Married (no.) & \\
Comorbid Conditions (no.) & 3 \\
$\quad$ Stable coronary artery disease & 7 \\
Systemic hypertension & 13 \\
Osteoarthritis & 7 \\
COPD & 5 \\
Diabetes mellitus & \\
& \\
* Data available for only 16 subjects. & \\
FVC = forced vital capacity & \\
$\mathrm{D}_{\text {LCO }}$ = diffusing capacity of the lung for carbon monoxide & \\
\hline
\end{tabular}

from baseline (Table 3). Among the 8 IPF subjects for whom we obtained follow-up 6MWD, the mean baseline $6 \mathrm{MWD}$ was $1,006 \pm 442$ feet, the post-PR 6MWD was $1,190 \pm 529$ feet, the mean change was 184 feet, the median change was 178 feet, and the change range was -265 feet to 680 feet. Mean 6MWD also improved after $\mathrm{PR}$ in the COPD comparison group, and there was no significant improvement difference between the IPF and COPD groups.

\section{Secondary Outcomes}

At baseline, the mean scores suggested substantial fatigue, at most mild anxiety and depression, mildly impaired sleep quality, and impaired health status, particularly in domains that tap physical health. Table 3 shows that after completion of PR the mean fatigue level improved significantly, and there were trends toward improved anxiety, depression, energy (as measured by the vitality domain of the SF-36), and physical health status (as measured by the physical component summary of the SF-36). Among the 8 subjects for whom we obtained follow-up data, there was no change from baseline to post-PR in percent-of-predicted FVC (73\% vs $73 \%, P=.9)$ or percent-of-predicted $\mathrm{D}_{\mathrm{LCO}}(38 \%$ vs $37 \%, P=.5)$.

\section{Discussion}

In this pilot study, PR significantly improved functional capacity and the less well recognized but perhaps equally burdensome symptom of fatigue. Fatigue is rarely assessed in IPF. Holland and colleagues found significant improvement with exercise in the Chronic Respiratory Questionnaire fatigue domain; however, that result was for the cohort as a whole, not for the IPF subgroup. ${ }^{13}$ To our knowledge, ours is the first study in IPF patients to assess the effect of PR on fatigue, measured with the Fatigue Severity Scale. In a study on sleep quality, Mermigkis et al administered the Fatigue Severity Scale to 15 subjects with IPF, and they found baseline scores similar to those in the present study. They also found a significant correlation $(\mathrm{r}=0.66)$ between mean nocturnal $\mathrm{S}_{\mathrm{pO}_{2}}$ and fatigue; thus, in their study nocturnal $\mathrm{S}_{\mathrm{pO}_{2}}$ explained $45 \%$ of the variance in fatigue scores. What other factors contribute to fatigue in patients with IPF is a question that merits further investigation.

Statistical models using data from this study showed that the mean improvement in 6MWD after PR was over 200 feet from baseline, a degree of improvement at least as great as that seen in our comparison group of patients with very severe COPD, and one that exceeded the value for the group-level minimum important difference for 6MWD in patients with IPF (92-98 feet $\left.{ }^{25,26}\right)$. There is a growing literature on the potential benefits of supervised exercise- or formal PR programs - on functional capacity in IPF. However, very few studies have examined the impact of PR on other meaningful outcomes such as fatigue and emotional health. In IPF, Nishiyama and colleagues ${ }^{14}$ observed a treatment effect of exercise of $46 \mathrm{~m}$ in 6MWD (average decline of $4 \mathrm{~m}$ in the control group, and average increase over $50 \mathrm{~m}$ in the exercise-program group) and a significant improvement in health-related quality of life (as measured with the Saint George's Respiratory Questionnaire total score). In a subgroup of 34 subjects with IPF, Holland et al $^{13}$ observed a mean 6MWD improvement of $25 \mathrm{~m}$ over baseline. However, the entirety of that gain and an additional $19 \mathrm{~m}$ was lost (for a total decline of $44 \mathrm{~m}$ ) at 6 months after completion of the PR program. Ferreira and colleagues conducted a before-and-after study of PR in 113 subjects with interstitial lung disease, 50 with IPF. ${ }^{12}$ Although the results for the IPF subgroup were not reported separately, PR significantly improved mean 6MWD, dyspnea, and psychological distress for the cohort as a whole.

We expected to observe more severe anxiety and depression than the General Anxiety Disorder scale and Patient Health Questionnaire-8 scores reflected. According to these scales, the overwhelming majority of our subjects had at most mild anxiety or depression. After PR the mean scores dropped-suggesting improvement in anxiety and depression-but the changes did not reach statistical significance. Whether these are the appropriate scales to use to quantify anxiety and depression in patients with IPF 
Table 2. Correlations Among Outcomes at Baseline

\begin{tabular}{|c|c|c|c|c|c|c|c|c|c|c|}
\hline & $\begin{array}{l}\text { 6MWD } \\
(\mathrm{r})\end{array}$ & $\begin{array}{l}\text { Nadir } \\
\mathrm{S}_{\mathrm{pO}_{2}} \\
(\mathrm{r}, P)\end{array}$ & $\begin{array}{c}\mathrm{FVC} \% \\
(\mathrm{r}, P)\end{array}$ & $\begin{array}{c}\mathrm{D}_{\mathrm{LCO}} \% \\
(\mathrm{r}, P)\end{array}$ & $\begin{array}{c}\text { Fatigue } \\
\text { Severity } \\
\text { Scale } \\
(\mathrm{r}, P)\end{array}$ & $\begin{array}{c}\text { General } \\
\text { Anxiety } \\
\text { Disorder } 7 \\
(\mathrm{r}, P)\end{array}$ & $\begin{array}{l}\text { Patient } \\
\text { Health } \\
\text { Question- } \\
\text { naire } 8 \\
(\mathrm{r}, P)\end{array}$ & $\begin{array}{l}\text { Pittsburgh } \\
\text { Sleep } \\
\text { Total } \\
(\mathrm{r}, P)\end{array}$ & $\begin{array}{c}\text { SF-36 } \\
\text { Physical } \\
(\mathrm{r}, P)\end{array}$ & $\begin{array}{c}\text { SF-36 } \\
\text { Vitality } \\
(\mathrm{r}, P)\end{array}$ \\
\hline 6MWD & 1.00 & $\begin{array}{c}0.66 \\
.002\end{array}$ & $\begin{array}{r}0.44 \\
.06\end{array}$ & $\begin{array}{r}0.28 \\
.30\end{array}$ & $\begin{array}{r}-0.57 \\
.01\end{array}$ & $\begin{array}{r}-0.04 \\
.89\end{array}$ & $\begin{array}{r}-0.32 \\
.20\end{array}$ & $\begin{array}{r}-0.37 \\
.13\end{array}$ & $\begin{array}{c}0.66 \\
.003\end{array}$ & $\begin{array}{r}0.32 \\
.19\end{array}$ \\
\hline Nadir $\mathrm{S}_{\mathrm{pO}_{2}}$ & NA & 1.00 & $\begin{array}{r}0.45 \\
.06\end{array}$ & $\begin{array}{r}0.57 \\
.02\end{array}$ & $\begin{array}{r}-0.42 \\
.09\end{array}$ & $\begin{array}{r}-0.13 \\
.62\end{array}$ & $\begin{array}{r}-0.13 \\
.58\end{array}$ & $\begin{array}{r}-0.39 \\
.11\end{array}$ & $\begin{array}{l}0.70 \\
.002\end{array}$ & $\begin{array}{r}0.10 \\
.70\end{array}$ \\
\hline $\mathrm{FVC} \%$ & NA & NA & 1.00 & $\begin{array}{r}0.44 \\
.09\end{array}$ & $\begin{array}{r}-0.12 \\
.63\end{array}$ & $\begin{array}{r}-0.34 \\
.16\end{array}$ & $\begin{array}{r}-0.25 \\
.30\end{array}$ & $\begin{array}{r}-0.54 \\
.02\end{array}$ & $\begin{array}{r}0.36 \\
.13\end{array}$ & $\begin{array}{r}0.06 \\
.82\end{array}$ \\
\hline $\mathrm{D}_{\mathrm{LCO}} \%$ & NA & NA & NA & 1.00 & $\begin{array}{r}-0.24 \\
.36\end{array}$ & $\begin{array}{r}-0.48 \\
.06\end{array}$ & $\begin{array}{r}-0.18 \\
.50\end{array}$ & $\begin{array}{r}-0.42 \\
.10\end{array}$ & $\begin{array}{r}0.43 \\
.10\end{array}$ & $\begin{array}{r}0.02 \\
.92\end{array}$ \\
\hline Fatigue Severity Scale & NA & NA & NA & NA & 1.00 & $\begin{array}{r}0.38 \\
.09\end{array}$ & $\begin{array}{r}0.53 \\
.01\end{array}$ & $\begin{array}{r}0.37 \\
.09\end{array}$ & $\begin{array}{l}-0.69 \\
<.001\end{array}$ & $\begin{array}{l}-0.71 \\
<.001\end{array}$ \\
\hline General Anxiety Disorder 7 & NA & NA & NA & NA & NA & 1.00 & $\begin{array}{l}0.59 \\
.005\end{array}$ & $\begin{array}{r}0.29 \\
.20\end{array}$ & $\begin{array}{r}-0.36 \\
.11\end{array}$ & $\begin{array}{r}-0.46 \\
.03\end{array}$ \\
\hline Patient Health Questionnaire 8 & NA & NA & NA & NA & NA & NA & 1.00 & $\begin{array}{l}0.59 \\
.005\end{array}$ & $\begin{array}{r}-0.27 \\
.24\end{array}$ & $\begin{array}{r}-0.50 \\
.02\end{array}$ \\
\hline Pittsburgh Sleep total & NA & NA & NA & NA & NA & NA & NA & 1.00 & $\begin{array}{r}-0.14 \\
.55\end{array}$ & $\begin{array}{r}-0.02 \\
.92\end{array}$ \\
\hline SF-36 physical & NA & NA & NA & NA & NA & NA & NA & NA & 1.00 & $\begin{array}{r}0.50 \\
.02\end{array}$ \\
\hline SF-36 vitality & NA & NA & NA & NA & NA & NA & NA & NA & NA & 1.00 \\
\hline \multicolumn{11}{|c|}{ 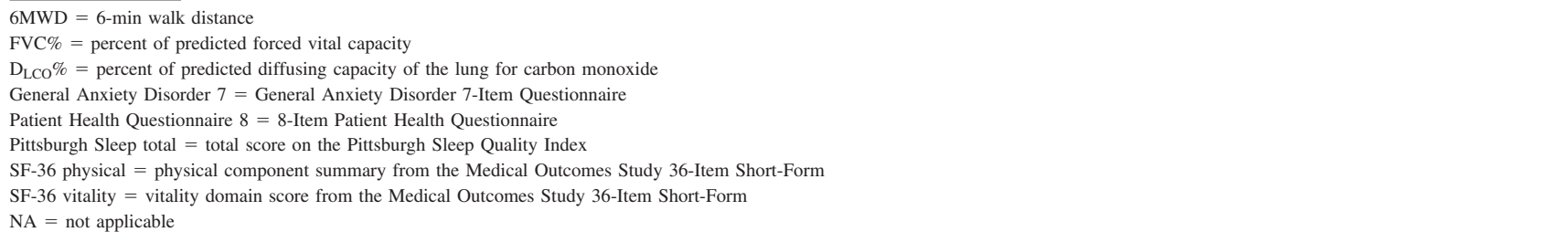 } \\
\hline
\end{tabular}

requires further study, but our opinion is that they possess the face validity to be useful in this population.

As with PR, there is growing interest in sleep quality and sleep disturbance in patients with IPF. ${ }^{24,27,28}$ One small study observed poorer sleep efficiency, a greater arousal index, and a greater percentage of time in stage I sleep in patients with IPF than in age-matched controls. ${ }^{24}$ Other investigators have observed poor sleep quality (as measured with the Pittsburgh Sleep Quality Index) in patients with IPF. Interestingly, they did not observe a correlation between sleep quality and 6MWD, oxygenation, or measures of pulmonary physiology, ${ }^{28}$ suggesting that sleep quality in patients with IPF is not strongly tied to disease severity. Paradoxically, in the present study, the Pittsburgh Sleep Quality Index score increased (suggesting worse sleep quality) after PR; however, the change was small and probably not clinically important.

We observed a pattern of poor health status (measured with the SF-36) that has been well established by several studies $^{29}$ of IPF patients: there are impairments in nearly every domain, but the greatest impairments are in SF-36 domains that tap aspects of physical health. Although the present study lacked the power to detect significant changes in any SF-36 domain, point estimates suggest improvement for every domain except Role Emotional. The strongest trends toward significant improvement after PR were in the Vitality domain (which assesses energy level or pep) and the Physical Component Summary.

\section{Limitations}

The primary limitations of this study are that the sample size was small and there was a substantial percentage of drop-outs. Attrition rates in other studies of exercise or PR in IPF range from $13-20 \% .^{13,14}$ In our study, only 2 subjects who started PR did not complete it-one because of back pain and one due to an IPF exacerbation. However, despite the drop-outs, we had adequate power to detect significant change in several secondary outcomes. Some subjects who dropped out cited the burden of travel to our center, and others noted conflicts with their daily schedule as their reasons not to enroll in PR. It must also be recognized that this 
Table 3. Repeated-Measures Analysis of Pulmonary Rehabilitation Effects on Functional Capacity, Fatigue, Anxiety, Depression, and Health Status*

\begin{tabular}{|c|c|c|c|c|}
\hline & Baseline & $\begin{array}{l}\text { After Pulmonary } \\
\text { Rehabilitation }\end{array}$ & Difference & $P \dagger$ \\
\hline \multicolumn{5}{|l|}{ 6-Min Walk Distance (feet) } \\
\hline IPF & $906 \pm 111$ & $1,108 \pm 164$ & $202 \pm 135$ & .01 \\
\hline \multirow[t]{2}{*}{ COPD } & $1,157 \pm 46$ & $1,225 \pm 47$ & $69 \pm 30$ & .03 \\
\hline & & & $134 \pm 82 \S$ & .10 \\
\hline Fatigue Severity Scale & $4.2 \pm 0.3$ & $2.7 \pm 0.5$ & $-1.5 \pm 0.5$ & .01 \\
\hline General Anxiety Disorder 7 & $2.7 \pm 0.8$ & $1.3 \pm 0.5$ & $-1.4 \pm 1.0$ & .1 \\
\hline Patient Health Questionnaire 8 & $3.4 \pm 0.0$ & $2.5 \pm 0.7$ & $-0.9 \pm 0.7$ & .2 \\
\hline Pittsburgh Sleep total & $5.9 \pm 0.7$ & $6.8 \pm 1.1$ & $0.9 \pm 0.8$ & .2 \\
\hline \multicolumn{5}{|l|}{ SF-36 } \\
\hline Physical functioning & $31.9 \pm 2.4$ & $33.1 \pm 2.8$ & $1.2 \pm 2.2$ & 6 \\
\hline Role physical & $36.4 \pm 2.3$ & $38.0 \pm 2.8$ & $1.5 \pm 2.0$ & .5 \\
\hline Bodily pain & $45.0 \pm 2.2$ & $47.6 \pm 2.7$ & $2.7 \pm 2.7$ & .3 \\
\hline General health & $38.3 \pm 1.7$ & $39.8 \pm 2.9$ & $1.4 \pm 2.8$ & 6 \\
\hline Vitality & $47.2 \pm 2.2$ & $50.8 \pm 2.6$ & $3.6 \pm 2.2$ & .1 \\
\hline Social functioning & $45.1 \pm 2.0$ & $47.1 \pm 3.0$ & $1.9 \pm 2.2$ & .4 \\
\hline Role emotional & $45.7 \pm 2.6$ & $43.8 \pm 4.0$ & $-1.9 \pm 4.3$ & .7 \\
\hline Mental health & $51.8 \pm 2.0$ & $53.3 \pm 1.4$ & $1.6 \pm 1.7$ & .4 \\
\hline Physical component summary & $33.1 \pm 1.9$ & $36.1 \pm 2.5$ & $3.0 \pm 2.1$ & .2 \\
\hline Mental component summary & $53.6 \pm 2.2$ & $53.9 \pm 2.5$ & $0.3 \pm 2.8$ & .9 \\
\hline \multicolumn{5}{|c|}{$\bar{*}$ Values are as mean \pm standard error. } \\
\hline \multicolumn{5}{|c|}{$\begin{array}{l}\dagger P \text { for comparison of baseline versus after pulmonary rehabilitation. } \\
\ddagger \text { For 6-min walk distance there was baseline data for } 14 \text { subjects and post-pulmonary rehabilitation data for } 8 \text { subjects (see text). For all other tests we obtained both baseline and post-pulmonary } \\
\text { rehabilitation data from } 14 \text { subjects. }\end{array}$} \\
\hline$\S$ Difference in 6-min walk distance betwee & . & tous patrits we & & \\
\hline & & & & \\
\hline \multirow{2}{*}{\multicolumn{5}{|c|}{$\begin{array}{l}\mathrm{D}_{\mathrm{LCO}} \%=\text { percent of predicted diffusing capacity of the lung for carbon monoxide } \\
\text { General Anxiety Disorder } 7=\text { General Anxiety Disorder 7-Item Questionnaire }\end{array}$}} \\
\hline & & & & \\
\hline \multicolumn{5}{|c|}{ Patient Health Questionnaire $8=8$-Item Patient Health Questionnaire } \\
\hline \multicolumn{5}{|c|}{ Pittsburgh Sleep total $=$ total score on the Pittsburgh Sleep Quality Index } \\
\hline SF-36 = Medical Outcomes Study 36-Item & & & & \\
\hline
\end{tabular}

was a highly motivated group of patients whose insurance covered the cost of PR, so our results may not apply to the general population of IPF patients. However, no potential subject was excluded based on inability pay for PR.

Another limitation of our study is the lack of an IPF control group. Without one, we cannot be certain that the changes we observed were due to PR. However, we have not come up with an alternative explanation.

Despite these limitations, this study adds to the growing literature in support of PR in patients with IPF. Based on the work of others, it is clear that PR improves functional capacity, and our study builds on Holland and colleagues' observation $^{13}$ that a supervised exercise regimen lessens fatigue-a very bothersome symptom - in patients with IPF. Although we did not observe significant improvements in health status in this study, other investigators have in their studies. ${ }^{13,14}$ The anxiety and depression improvements we found did not reach statistical significance, but we believe that these are important outcomes to measure, that PR probably improves them, and that a larger study will confirm that belief. Finally, highlighting the variable behavior of IPF, 2 subjects experienced
IPF exacerbations: one within a week of the insertion of a transtracheal oxygen catheter (after completion of PR but prior to follow-up), and one shortly after starting the PR program. There are no good predictors-including pulmonary physiology — of which patients will develop exacerbations, and these 2 patients had no contraindications to PR. Nonetheless, it is prudent to carefully assess IPF patients for their ability to exercise safely prior to enrolling them in a PR program.

Hopefully, the momentum generated by this and other recent studies will promote further investigation of PR in IPF and answer several questions, including should a PR program for patients with IPF last longer than the standard 6 weeks, or even carry on indefinitely to maintain the benefits? In a recently published study of the effects of out-patient PR in 31 patients with restrictive lung disease (11 with interstitial lung disease), Salhi et al observed improvements in 6MWD from baseline in subjects who participated in PR for 12 weeks; further gains in mean 6MWD were observed in subjects who remained in PR for 24 weeks. $^{30}$ 


\section{Benefits of Pulmonary Rehabilitation in Idiopathic Pulmonary Fibrosis}

When IPF patients complete PR, are they carrying on at home what they learned during the PR program? Holland and colleagues observed that 6MWD, dyspnea scores, and Chronic Respiratory Questionnaire scores waned to baseline by 6 months after completion of PR. Although they encouraged their subjects to continue exercising at home after the formal exercise program, ${ }^{13}$ there was no systematic assessment of the subjects' activity. Perhaps after completion of a formal PR or exercise program, monthly standardized activity questionnaires should be collected from subjects. Such data would help determine if continued adherence to a home exercise regimen sustains PR benefits. Finally, whether the exercise or other components of standard PR programs - designed for patients with COPD—need to be modified to better suit patients with IPF requires further study.

\section{Conclusions}

A standard PR program improved functional capacity in patients with IPF, and significantly improved fatigue, which is an underappreciated and bothersome symptom of IPF. Several important questions about exercise and the effects of PR in patients with IPF remain but can be answered with carefully designed, prospective studies.

\section{REFERENCES}

1. American Thoracic Society. Idiopathic pulmonary fibrosis: diagnosis and treatment. International consensus statement. American Thoracic Society (ATS), and the European Respiratory Society (ERS). Am J Respir Crit Care Med 2000;161(2 Pt 1):646-664.

2. Olson AL, Swigris JJ, Lezotte DC, Norris JM, Wilson CG, Brown KK. Mortality from pulmonary fibrosis increased in the United States from 1992 to 2003. Am J Respir Crit Care Med 2007;176(3):277-284.

3. Nishiyama $\mathrm{O}$, Taniguchi $\mathrm{H}$, Kondoh $\mathrm{Y}$, Kimura T, Kato K, Ogawa $\mathrm{T}$, et al. Dyspnoea at 6-min walk test in idiopathic pulmonary fibrosis: comparison with COPD. Respir Med 2007;101(4):833-838.

4. Nishiyama O, Taniguchi H, Kondoh Y, Kimura T, Ogawa T, Watanabe $\mathrm{F}$, et al. Health-related quality of life in patients with idiopathic pulmonary fibrosis. What is the main contributing factor? Respir Med 2005;99:408-414.

5. Swigris JJ, Kuschner WG, Jacobs SS, Wilson SR, Gould MK. Healthrelated quality of life in patients with idiopathic pulmonary fibrosis: a systematic review. Thorax 2005;60(7):588-594.

6. Swigris JJ, Stewart AL, Gould MK, Wilson SR. Patients' perspectives on how idiopathic pulmonary fibrosis affects the quality of their lives. Health Qual Life Outcomes 2005;3:61.

7. Swigris JJ, Brown KK, Make BJ, Wamboldt FS. Pulmonary rehabilitation in idiopathic pulmonary fibrosis: a call for continued investigation. Respir Med 2008;102(12):1675-1680.

8. Nici L, Donner C, Wouters E, Zuwallack R, Ambrosino N, Bourbeau $\mathrm{J}$, et al. American Thoracic Society/European Respiratory Society statement on pulmonary rehabilitation. Am J Respir Crit Care Med 2006;173(12):1390-1413.

9. Bianchi R, Gigliotti F, Romagnoli I, Lanini B, Castellani C, Grazzini $\mathrm{M}$, et al. Chest wall kinematics and breathlessness during pursed-lip breathing in patients with COPD. Chest 2004;125(2):459-465.

10. Bernard S, Whittom F, Leblanc P, Jobin J, Belleau R, Berube C, et al. Aerobic and strength training in patients with chronic obstructive pulmonary disease. Am J Respir Crit Care Med 1999;159(3):896-901.
11. Mador MJ, Kufel TJ, Pineda LA, Steinwald A, Aggarwal A, Upadhyay $\mathrm{AM}$, et al. Effect of pulmonary rehabilitation on quadriceps fatiguability during exercise. Am J Respir Crit Care Med 2001;163(4):930-935.

12. Ferreira A, Garvey C, Connors GL, Hilling L, Rigler J, Farrell S, et al. Pulmonary rehabilitation in interstitial lung disease: benefits and predictors of response. Chest 2009;135(2):442-447.

13. Holland AE, Hill CJ, Conron M, Munro P, McDonald CF. Short term improvement in exercise capacity and symptoms following exercise training in interstitial lung disease. Thorax 2008;63(6):549-554.

14. Nishiyama O, Kondoh Y, Kimura T, Kato K, Kataoka K, Ogawa T, et al. Effects of pulmonary rehabilitation in patients with idiopathic pulmonary fibrosis. Respirology 2008;13(3):394-399.

15. Kozora E, Emery CF, Ellison MC, Wamboldt FS, Diaz PT, Make B. Improved neurobehavioral functioning in emphysema patients following lung volume reduction surgery compared with medical therapy. Chest 2005;128(4):2653-2663.

16. Fishman A, Martinez F, Naunheim K, Piantadosi S, Wise R, Ries A, et al; National Emphysema Treatment Trial Research Group. A randomized trial comparing lung-volume-reduction surgery with medical therapy for severe emphysema. N Engl J Med 2003;348(21):2059-2073.

17. Swigris JJ, Swick J, Wamboldt FS, Sprunger D, du Bois R, Fischer A, et al. Heart rate recovery after 6-minute walk test predicts survival in patients with idiopathic pulmonary fibrosis. Chest 2009;136(3):841-848.

18. Hankinson JL, Odencrantz JR, Fedan KB. Spirometric reference values from a sample of the general US population. Am J Respir Crit Care Med 1999;159(1):179-187.

19. Crapo RO, Morris AH. Standardized single breath normal values for carbon monoxide diffusing capacity. Am Rev Respir Dis 1981;123(2): 185-189.

20. Krupp LB, LaRocca NG, Muir-Nash J, Steinberg AD. The fatigue severity scale. Application to patients with multiple sclerosis and systemic lupus erythematosus. Arch Neurol 1989;46(10):1121-1123.

21. Spitzer RL, Kroenke K, Williams JB, Lowe B. A brief measure for assessing generalized anxiety disorder: the GAD-7. Arch Intern Med 2006;166(10):1092-1097.

22. Kroenke K, Strine TW, Spitzer RL, Williams JB, Berry JT, Mokdad AH. The PHQ-8 as a measure of current depression in the general population. J Affect Disord 2009;114(1-3):163-173.

23. Buysse DJ, Reynolds CF, 3rd, Monk TH, Berman SR, Kupfer DJ. The Pittsburgh Sleep Quality Index: a new instrument for psychiatric practice and research. Psychiatry Res 1989;28(2):193-213.

24. Mermigkis C, Stagaki E, Amfilochiou A, Polychronopoulos V, Korkonikitas P, Mermigkis D, et al. Sleep quality and associated daytime consequences in patients with idiopathic pulmonary fibrosis. Med Princ Pract 2009;18(1):10-15.

25. Holland AE, Hill CJ, Conron M, Munro P, McDonald CF. Small changes in six-minute walk distance are important in diffuse parenchymal lung disease. Respir Med 2009;103(10):1430-1435.

26. Swigris JJ, Wamboldt FS, Behr J, du Bois RM, King TE, Raghu G, et al. The 6 minute walk in idiopathic pulmonary fibrosis: longitudinal changes and minimum important difference. Thorax 2010;65(2): 173-177.

27. Agarwal S, Richardson B, Krishnan V, Schneider H, Collop NA, Danoff SK. Interstitial lung disease and sleep: what is known? Sleep Med 2009;10(9):947-951.

28. Krishnan V, McCormack MC, Mathai SC, Agarwal S, Richardson B, Horton MR, et al. Sleep quality and health-related quality of life in idiopathic pulmonary fibrosis. Chest 2008;134(4):693-698.

29. Swigris JJ, Gould MK, Wilson SR. Health-related quality of life among patients with idiopathic pulmonary fibrosis. Chest 2005; 127(1):284-294.

30. Salhi B, Troosters T, Behaegel M, Joos G, Derom E. Effects of pulmonary rehabilitation in patients with restrictive lung diseases. Chest 2010;137(2):273-279. 